\title{
ENALLTerm: hacia una base de datos al servicio de la traducción especializada ${ }^{1}$
}

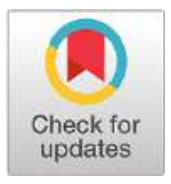

\author{
loana Cornea \\ ioana.cornea@enallt.unam.mx \\ https://orcid.org/0000-0002-7990-869X \\ Universidad Nacional Autónoma de México, México
}

\section{Resumen}

El objetivo de este artículo es describir el proceso de creación y diseño de la base de datos terminológica para la traducción ENALLTerm. Este recurso terminológico, de libre acceso, está dirigido a los estudiantes de traducción de la Escuela Nacional de Lenguas, Lingüística y Traducción (ENALLT) de la Universidad Nacional Autónoma de México, pero también a usuarios externos interesados en la actividad de traducción. Este estudio interdisciplinario, basado en la teoría comunicativa de la terminología, de María Teresa Cabré, y en la lexicografía funcional, de Sven Tarp, se plantea suplir las deficiencias terminológicas que puede tener un traductor durante el proceso traductor. La metodología integra los trabajos de terminología de los estudiantes del Diplomado en Traducción de Textos Especializados de la ENALLT y de la Licenciatura en Traducción de la misma escuela. A través de la plataforma de ENALLTerm, los alumnos pueden rellenar los diferentes campos de las fichas, en una combinación lingüística inglés, francés o alemán al español. Luego, las fichas pasan por un proceso de revisión externo, efectuado por un especialista en el ámbito temático en cuestión, y por una revisión interna, de tipo lingüístico, que la hacer el equipo de ENALLTerm. Las fichas se centran en recopilar información traductológica como, por ejemplo, tipos de equivalentes, contextos de uso y contextos multimedia (fotos, audios, videos), opciones de traducción no recomendadas y comentarios para la traducción.

Palabras clave: ENALLTerm; recursos para la traducción especializada; terminología aplicada a la traducción; fichas traductológicas.

\section{ENALLTerm: Towards a Specialized Translation-Oriented Terminological Database}

\begin{abstract}
The aim of this study is to describe the process of creating the ENALLTerm terminological database. The resource is designed for use by translation students at the School of Languages, Linguistics and Translation (ENALlT) at UNAM, Mexico, but it may also be used by others with an interest in translation. This interdisciplinary study is based on Maria Teresa Cabre's Communicative Theory of Terminology (TCT) and Sven Tarp's Functional Lexicography. Some terminological databases are not specifically designed for translators or translation practice. To meet translators' needs, a unique database must be created with

1 La investigación "Léxico y tecnología: la elaboración de la base de datos terminológica ENALLTerm" ha sido financiada por el Programa de Apoyo a Proyectos de Investigación e Innovación Tecnológica de la Universidad Nacional Autónoma de México (UnAm) (IT400420).
\end{abstract}


the goal of helping translators solve terminological challenges during the translation process. The methodology employed incorporates terminology projects by students of the Certificate in Specialized Translation and Bachelor's degree in Translation at ENALLT. Using the ENALLTerm website, students can fill in the different fields of the terminological entries in language combinations consisting of English, French or German into Spanish. The terminological entries then undergo an external review process by a subject-matter specialist and an internal linguistic review by the ENALLTerm team. The entries mainly consist of translation-oriented information, such as type of equivalent, context of use, multimedia context (photo, audio, video), non-recommended translations and transfer comments.

Keywords: ENALLTerm; tools for specialized translation; terminology applied to translation; translation-oriented terminological entries.

\section{ENALLTerm : vers une base de données au service de la traduction spécialisée}

\section{Résumé}

L'objectif de cette recherche est de décrire le processus de création de la base de données terminologique de traduction ENALLTerm. Cette ressource terminologique, librement accessible, est destinée aux étudiants en traduction de l'École nationale de langues, de la linguistique et de la traduction (ENALLT) de l'unAm, Mexique, mais aussi aux utilisateurs externes intéressés par l'activité de traduction. La présente étude interdisciplinaire est basée sur la théorie communicative de la terminologie, de Maria Teresa Cabré, et la lexicographie fonctionnelle, de Sven Tarp. La méthodologie intègre le travail de terminologie des étudiants du Diplôme en Traduction de Textes Spécialisés de l'Enalte et de la Licence de Traduction de la même Ecole. Grâce à la plateforme ENALLTerm, les étudiants peuvent remplir les différents champs des fiches dans une combinaison de langues anglais, français ou allemand vers l'espagnol. Ensuite, les fiches passeront par une révision externe par le spécialiste du domaine thématique concerné et une révision interne, à caractère linguistique, par l'équipe ENALLTerm. Les fiches se concentreront sur la collecte d'informations de traduction telles que les types d'équivalents, les contextes d'utilisation et les contextes multimédias (photos, audios, vidéos), les options de traduction non recommandées et les commentaires pour la traduction.

Mots-clés : eNALLTerm ; ressources pour la traduction spécialisée ; terminologie appliquée à la traduction; entrées terminologiques pour la traduction. 


\section{Introducción}

Vivimos rodeados de terminología: leemos terminología en el prospecto de algún medicamento, en la etiqueta del jabón que usamos cada día o en algún trámite administrativo que debemos realizar. Sin embargo, ¿sabemos tratar esa terminología? ¿Somos expertos en cada dominio? El avance de Internet y las nuevas tecnologías nos llevan a un contexto donde la terminología está cada vez más presente en nuestros lugares de trabajo, en nuestros hogares, en nuestra vida. Si bien antes considerábamos la terminología como algo muy propio de las disciplinas consagradas, como la medicina, la economía, el derecho o la arquitectura, en la actualidad podemos afirmar que la terminología es parte de la realidad de nuestro día a día. Esto no implica que la terminología se banalice, pero sí se generaliza, por lo que necesitamos más recursos lexicográficos y terminológicos que recopilen estos inventarios especializados y los pongan a disposición de los usuarios.

Los usuarios, con diferentes perfiles y necesidades, recurren a estos recursos para resolver diversos problemas terminológicos, desde la comprensión de un término hasta el análisis de las relaciones conceptuales que se crean entre varios términos de un ámbito de especialidad específico. Todos nos acercamos a la terminología; sin embargo, cada uno lo hace con diversas finalidades. Los principales usuarios y consumidores de las terminologías son los traductores e intérpretes, quienes requieren de distinto tipo de información lingüística y enciclopédica para poder llevar a cabo su trabajo.

Para transmitir el conocimiento especializado, los traductores e intérpretes deben emplear una terminología adecuada en cada contexto, emprender y crear recursos que les permitan guardar los valores de la lengua y cultura, recopilar unidades léxicas específicas de los dominios de la sociedad, de la sociedad de cada uno, porque hay que dar tratamiento a la terminología desde la realidad de cada país, organismo, institución, etc. En pocas palabras, esto se refiere al principio de adecuación (Cabré, 1999, p. 137), uno de los fundamentos que rige la confección y el diseño de productos terminológicos.

En México no existe ninguna base de datos terminológica centrada en el proceso de traducción y mucho menos un producto en el cual los estudiantes participen de forma activa a través de la creación de fichas traductológicas, que contienen información como variante de traducción, opciones no recomendadas y comentarios.

Por esta razón, se hizo necesario y útil crear un recurso terminológico, de libre acceso, dirigido a los estudiantes de traducción e interpretación de la Escuela Nacional de Lenguas, Lingüística y Traducción (ENALLT) de la Universidad Nacional Autónoma de México (UNAM), a traductores e intérpretes profesionales de México, pero también a usuarios externos interesados en el uso de la terminología.

Como se puede ver, en este artículo nos proponemos describir el proceso de creación y diseño de la base de datos traductológica ENALLTerm, denominación que surge de la combinación de la sigla de la Escuela Nacional de Lenguas, Lingüística y Traducción, y la abreviatura "term", de "terminología".

Para cumplir con este objetivo, analizamos las principales bases de datos terminológicas para observar qué tipo de información contienen y de esta forma proponer un recurso innovador. También realizamos una encuesta sobre la utilidad de las categorías de datos de la ficha ENALLTerm, previamente diseñada, con el fin de validar las categorías existentes y obtener la opinión de los futuros usuarios, a saber, los estudiantes de traducción e interpretación, y los traductores e intérpretes profesionales de México, 
por si se requiere incluir más información relacionada con el proceso traductor. Asimismo, construimos un corpus a partir de los trabajos terminológicos (glosarios) de los estudiantes del Diplomado en Traducción de Textos Especializados y la Licenciatura en Traducción de la ENALLT que cursaron la asignatura Terminología para Traductores y diferentes talleres de traducción especializada, en los cuales se realizan traducciones y crean glosarios en varios ámbitos de especialidad. El corpus se representa gráficamente mediante fichas traductológicas en la base de datos en formato web.

El artículo está estructurado en las siguientes partes: a continuación presentamos el marco teórico que sustenta nuestra investigación, en el cual abordamos estudios sobre terminología aplicada a la traducción especializada, así como estudios sobre la competencia traductora que nos permitan observar el perfil del traductor y sus necesidades en el proceso traductor. Luego, presentamos la metodología, seguida de la descripción de la plataforma web que alberga la base de datos traductológica ENALLTerm y finalizamos con las conclusiones.

\section{Los recursos terminológicos y el proceso de traducción}

El proyecto de la elaboración de la base de datos traductológica ENALLTerm tuvo como propósito consolidar la relación de sinergia y convergencia existente entre las áreas de lexicografía, terminología y traducción especializada, lo que constituye el fundamento previo para establecer las bases de un recurso terminológico para la traducción.

La traducción de textos especializados de diferentes ámbitos —o simplemente, la traducción técnica, jurídica, económica o médica - contiene conceptos que van más allá de lo lingüístico y obligan al traductor a poseer conocimientos temáticos, terminológicos, textuales, etcétera. De tal manera que las características de la traducción especializada se reflejan en el tipo de problemas que debe resolver un traductor, quien no siempre es un experto en ese campo. En consecuencia, un traductor sin formación en un ámbito de especialidad, por ejemplo, debe documentarse y adquirir el conocimiento especializado de la materia, para poder llevar a cabo una traducción de calidad.

En la traducción especializada, los problemas de traducción más frecuentes son los terminológicos, debido a la presencia de unidades léxicas especializadas o unidades terminológicas (UT) (Cabré y Estopà, 2002, p. 148). Estas unidades se caracterizan por "el tipo de conocimiento que transmiten (condiciones cognitivas y semánticas) y el uso de su discurso (condiciones pragmáticas-discursivas)" (Cabré y Estopà, 2005 , p. 7). Las UT crean redes que transmiten el conocimiento especializado, y se relacionan entre sí, configurando la estructura cognitiva de un texto. Por tanto, no es de extrañar que constituyen los problemas principales en una traducción, ya que engloban lo lingüístico, lo cognitivo y lo comunicativo.

E1 traductor, novato o experto, necesita tratar adecuadamente la terminología del ámbito que le corresponde traducir, para alcanzar, en su traducción, el nivel de especialización requerido. El tratamiento de la terminología en una traducción no implica solamente buscar equivalentes (necesidades léxicas), sino también comprender esos equivalentes, asociarlos o diferenciarlos de otros para evitar confusiones, lo que supone un conocimiento especializado de la materia (necesidades conceptuales). E1 traductor actúa como mediador entre los interlocutores de la comunicación especializada, y para cumplir su objetivo debe tener suficiente competencia en la materia para entender el mensaje del especialista y poder transferirlo a los demás receptores, especialistas o no. No obstante, estos conocimientos se requieren en la 
lengua origen y meta, por cuanto el traductor necesita información conceptual y traductológica que le permita comprender de forma contrastiva los términos para la toma de decisiones.

Como traductores, siempre recurrimos a los productos lexicográficos y terminográficos (diccionarios especializados, diccionarios bilingües, glosarios, bases de datos terminológicos) para poder resolver los problemas de traducción. Algunos de estos productos son las bases y los bancos de datos terminológicos que resultan de la elaboración de un trabajo terminológico.

Montané March especifica que la función de los trabajos terminológicos es "recopilar términos y organizar la información relacionada, agrupándola en fichas terminológicas que siguen un modelo uniforme" (2016, p. 115). Las fichas terminológicas contienen términos pertenecientes a diversos ámbitos temáticos $\mathrm{y}$ algunas categorías de datos que suelen ser fijas, aunque pueden diferir de una base a otra, según sus destinatarios, función, objetivos. Las categorías de datos que normalmente se encuentran en una ficha son: entrada, información gramatical, fuente, marcas de uso, área temática, definición, notas, contextos (sintaxis, combinatoria e incluso rasgos semánticos), equivalencias, entre otras (Montané March, 2016, p. 120). Estas categorías se podrían representar en el término, dando lugar a productos monolingües con equivalencias, o de ambos lados, tanto del término como del equivalente, formando los recursos bilingües.

Los estudios sobre los productos lexicográficos y terminológicos bilingües presentan algunas limitaciones de los productos actuales, como veremos en los estudios de Bestué Salinas (2016), Biel (2008), Tarp (2010, 2014) y Van Laer (2014). Además, estas investigaciones destacan la utilidad de contar con información para la traducción, ya que un recurso es una herramienta útil para la traducción si contiene los elementos necesarios para responder a las fases del proceso traductor: pretraducción, traducción y postraducción (Tarp, 2010). Ante una situación de traducción, que implica la comparación entre dos lenguas y culturas, los productos terminológicos bilingües deberían considerar información contrastiva para que el traductor pueda darse cuenta de las diferencias que existen entre las unidades presentadas (Durão et al., 2012, pp. 71-73) y tomar la decisión más adecuada en función de su situación de traducción. No obstante, la información contrastiva no se recopila en muchos productos terminológicos bilingües, ya que, por un lado, describen el término y, por otro, el equivalente, pero no los contrasta (por ejemplo, IATE, UNTERM). ${ }^{2}$

Además, si observamos otros recursos como los corpus multilingües y diccionarios bilingües basados en corpus (como Linguee), muy presentes en la web, la situación se complica aún más, ya que estos recursos obligan al traductor a simplificar el proceso de selección de términos, debido a las frases ya traducidas y categorizadas como válidas. En este sentido, Bestué Salinas (2016) apunta que los traductores prefieren elegir un equivalente que ya ha sido validado por otros traductores $\mathrm{y}$, por lo tanto, califican su traducción como adecuada. En sus palabras:

La elección de uno u otro equivalente suele estar justificada por el hecho de que haya sido utilizado previamente por otros traductores y por la comunidad receptora. Cuando los traductores confirman así la existencia de un

2 La Terminología Interactiva para Europa (Interactive Terminology for Europe, IATE) es la base de datos terminológica de la Unión Europea (véase Unión Europea, 2021); por su parte, UNTERM (The United Nations Terminology Database) es la Base de Datos Terminológica de Naciones Unidas (véase Naciones Unidas, 2013). 
equivalente, consideran validada su elección y dan por buena la traducción (Bestué Salinas, 2016, p. 4; traducción propia). ${ }^{3}$

Sin embargo, esto no garantiza la calidad de la traducción; incluso, se complica para muchos traductores novatos o expertos, quienes optan por la traducción más común que aparece en estos productos:

Los traductores novatos suelen adoptar este método como criterio principal a la hora de validar los equivalentes. Los traductores expertos que, según Pym (2008), tienen una aversión natural al riesgo, suelen recurrir también a este método, en particular cuando se trata de textos especializados (Bestué Salinas, 2016, p. 2; traducción propia). ${ }^{4}$

Así, se puede ver que el conocimiento insuficiente del traductor sobre el ámbito especializado, como también la carencia de una documentación adecuada por cuestiones de tiempo, dificulta su labor, al tener que destinar tiempo y recursos en elegir el equivalente más adecuado para su contexto, por lo que adoptan las variantes ya sugeridas, sin asumir argumentos propios en la toma de decisiones.

Además, los diccionarios bilingües presentan todavía muchas limitaciones en cuanto a su uso en el proceso de traducción y no cumplen con las expectativas de los traductores especializados, quienes esperan encontrar información lingüística y conceptual (Orozco-Jutorán, 2017).

3 "The choice of one or another equivalent is often justified by its having been previously used by other translators and the receiving community. When translators confirm the existence of an equivalent in this way they consider their choices validated and assume the translation to be acceptable".

4 "Novice translators typically adopt this method as their main criterion when validating equivalents. Expert translators who, according to Pym (2008), have a natural aversion to risk-taking, often rely on this method too, in particular when dealing with specialist texts".
Tarp (2014, p. 80) destaca que los diccionarios en línea son básicamente copias de los diccionarios en papel y en muy pocos casos se han adaptado a las necesidades de los usuarios, mientras que Biel (2008, p. 29) apunta que los diccionarios especializados normalmente presentan listas de equivalentes descontextualizados, sin colocaciones ni ejemplos de uso.

Estos ejemplos teóricos demuestran que los productos lexicográficos y terminológicos existentes aún no alcanzan a cubrir las necesidades de los traductores en una actividad de traducción. Van Laer (2014, p. 75) menciona el caso de los diccionarios jurídicos y dice que son útiles en la medida en que añaden explicaciones a sus listas de palabras, pero siguen sin satisfacer plenamente las necesidades de los traductores jurídicos. Sin embargo, esta situación se puede extrapolar a otros tipos de traducción especializada, ya que estas necesidades están vinculadas con las competencias que un usuario debe poseer (Nielsen, 2010, p. 73).

\section{La competencia traductora}

Las diferentes investigaciones sobre la competencia traductora (Kelly, 2008, 2014; Hurtado Albir, 2007, 2017; РАCTE, 2003, 2014, 2018) han sistematizado, a partir de estudios empíricos, las (sub)competencias requeridas para un traductor. Sin presentar aquí todos los modelos ya mencionados, dado que no es el objetivo de este trabajo, nos centramos en los modelos de PACTE $(2003,2018)$ y Hurtado Albir (2007), por su relevancia en este campo y por la propuesta innovadora en cuanto a la nivelación de competencias en la adquisición de la competencia traductora. Las diferentes denominaciones que estos modelos utilizan para referirse a una competencia u otra son:

- Competencia bilingüe/lingüística comunicativa. 
- Competencia extralingüística/cultural, enciclopédica y temática.

- Competencia textual.

- Conocimientos de traducción/ provisión de servicios de traducción/profesional.

- Competencia instrumental.

- Competencia estratégica/metodológica o de resolución de problemas de traducción.

De estas competencias, nos detenemos en las que pueden representarse en un recurso terminológico para la traducción, así que descartamos la competencia relacionada con los conocimientos de traducción/provisión de servicios de traducción/profesional, vinculada con el mercado de trabajo, y la competencia instrumental, ya que estamos diseñando una herramienta documental para la práctica traductora; sin embargo, el traductor deberá poseer la competencia de manejo de distintos recursos y fuentes documentales, y esta base de datos es uno de ellos.

La competencia bilingüe/lingüistica/comunicativa se relaciona con el conocimiento de las dos lenguas implicadas en un proceso de traducción. Aquí cabe mencionar la propuesta de Hurtado Albir (2007), quien afirma que no es suficiente tener conocimientos sobre las dos lenguas, sino que estos conocimientos sean contrastivos, es decir, conocer las diferencias entre las dos lenguas implicadas en un proceso de traducción y con el control de interferencias, información que puede hallarse en fichas terminológicas bilingües. En este sentido, el modelo de PACтE (2018) determina la competencia lingüística según los niveles lingüísticos del Marco Común Europeo de Referencia (MCER). $\mathrm{E} 1$ nivel A de traducción requiere un nivel B2 en comprensión lectora y de nivel $\mathrm{C} 1$ de producción escrita del MCER, mientras que el nivel $\mathrm{C}$ de traducción requiere un nivel C2 del MCER, en ambos casos (PACTE, 2018, p.10).
La competencia extralingüistica/cultural, enciclopédica y temática permite movilizar los conocimientos de la cultura de origen y meta, y los conocimientos de carácter general y temáticos de los ámbitos de especialización, con el fin de solucionar los problemas de traducción. En una traducción especializada es sumamente importante poseer conocimientos temáticos para la comprensión global del texto, pues esto favorece la identificación y el tratamiento adecuado de la terminología. Delimitar este tipo de conocimientos es bastante complicado, ya que cada texto especializado tiene su especificidad y nivel de dificultad temática, del mismo modo que cada traductor, que no cuenta con formación en la materia, posee los conocimientos temáticos en función de su experiencia en dicho ámbito. No obstante, PACTE (2018, pp. 8-9) intenta sistematizar los conocimientos que un traductor debería poseer en cada uno de los niveles y apunta que, en el nivel A, el traductor es capaz de traducir textos no especializados; en el nivel B, textos semiespecializados, mientras que, en el nivel $\mathrm{C}$, textos especializados de, al menos, un ámbito profesional de especialización de la traducción (jurídico, económico y financiero, técnico, científico, literario, audiovisual, accesibilidad, localización, etc.), aunque, afirman, este nivel queda por desarrollar. La información relacionada con el ámbito temático puede representarse mediante las definiciones, los contextos de uso y las ligas de interés para adquirir esta competencia extralingüística en una sola búsqueda.

Por otro lado, el carácter especializado del texto obliga al traductor a poseer conocimientos conceptuales de la disciplina o subdisciplina en sí, pero también de los géneros textuales más comunes de ese ámbito. En este sentido, la competencia textual permite solucionar problemas de traducción que surgen de las particularidades de los diferentes géneros textuales. Uno de los recursos empleados con más frecuencia 
por los traductores son los textos paralelos, en los cuales se buscan elementos paratextuales y textuales, para facilitar la toma de decisiones.

La competencia estratégica/metodológica o de resolución de problemas de traducción hace referencia a los principios y las estrategias de tipo metodológico necesarios para llevar a cabo el proceso de traducción, que permitirán encontrar la solución más conveniente a los problemas traductológicos en cada caso. El traductor debe ser capaz de identificar y resolver problemas de traducción propios de los textos poco o altamente especializados. La dificultad no radica en los textos con un nivel bajo de especialización, sino en aquellas comunicaciones que se realizan entre expertos y que cuentan con mucha terminología; por eso, los traductores recurren a los productos terminológicos

\section{Recursos traductológicos para el proceso de traducción}

Ahora bien, si relacionamos la competencia traductora con el supuesto objetivo de que los diccionarios deberían satisfacer las necesidades específicas de los usuarios - determinadas por un tipo de situación concreta (Householder, 1960, en Fuertes Olivera y Tarp, 2008, p. 78) - , nos encontramos ante una carencia de productos terminológicos que asistan a los traductores en la actividad de traducción. A partir del análisis que realizamos de quince bases de datos terminológicas, que presentamos en detalle en el siguiente apartado, observamos que la representación lexicográfica de datos que apoyen al proceso de traducción se limita a comentarios o notas, y variantes de traducción, mientras que solo un recurso recopila opciones no recomendadas y ninguno hace mención alguna de las técnicas de traducción. Incluso, la información conceptual solo se representa mediante contextos, pero la mayoría de los recursos no recopila material multimedia: audio, foto, video, que podría facilitar la comprensión del término y del equivalente.

Un diccionario bilingüe para la traducción debe responder a las fases del proceso de traducción y asistir al traductor en resolver los problemas de traducción que surgen (Tarp, 2010, p. 10). El proceso traductor incluye las fases de planificación, ejecución y finalización (Nord, 1991), por lo que el traductor debe poseer los conocimientos específicos para cumplir con cada paso. Las necesidades lexicográficas del traductor se vinculan más bien con la etapa de ejecución, que implica el análisis del texto origen (то), la traducción y la producción del texto meta (TM), y la etapa de finalización, que se refiere a la revisión del TM. Esto ha llevado a una relación estrecha con la actividad lexicográfica, porque el traductor necesita las obras lexicográficas para resolver diversos problemas. Así que, en el proceso de análisis del то, el traductor se sirve de sus conocimientos del tema textual, terminología, dominio de la lengua y cultura de origen, es decir, vocabulario, sintaxis, estilística y textualización. Asimismo, en la etapa de producción del TM, el traductor debe recurrir a conocimientos temáticos y terminológicos, o lingüísticos y culturales en la lengua meta. En la última fase, la de finalización, el diccionario desempeña un papel importante para la revisión y corrección del texto traducido.

En caso de que el traductor no posea estos conocimientos, se convierten en una necesidad que debe cubrir para llevar a cabo el proceso completo. Los tipos de necesidades del traductor son de naturaleza léxica (terminológica), textual y temática, tanto en la lengua de origen como meta. El producto terminológico debería ocupar un lugar preferente en la resolución de dudas del traductor especializado y los campos deberían moldearse en función de sus necesidades. 
Lo anterior remite al principio de adecuación, que se enmarca en las innovaciones teóricas-metodológicas de la teoría comunicativa de la terminología (ТСТ) (Cabré, 1999, p. 137). Dicho principio se refiere a fundamentos que deben establecerse en relación con el destinatario y sus necesidades, el tema, el soporte y el tipo de diccionario (Cabré, 1999). Estos elementos impulsan a la selección de una técnica de elaboración del diccionario, que se adapta según cada situación. Como bien indica Cabré:

La metodología pues, lejos de actuar como un corsé, se adapta a las circunstancias sin contravenir los principios; la adecuación metodológica está por encima de la unificación extrema. [...]. En todos los casos se respetarán los mínimos, pero cada uno adecuará la metodología a sus circunstancias (1999, p. 133).

La teoría comunicativa de la terminología determina diferentes categorías de información: fonética, morfológica (sufijos, prefijos), remisiones (sinónimos, antónimos, etc.), sintáctica (contextos, ejemplos), semántica (definiciones, contextos definitorios), pragmática (relación con los árboles de campo, marcas de variación lingüística), ilustraciones, fotografías, símbolos (Cabré et al., 2018, pp. 184-186). Esta información puede aparecer representada en fichas monolingües, monolingües con equivalencias, o bilingües. No obstante, observamos que este tipo de información es de orden más bien lingüístico y muy poco conceptual, mientras que la información traductológica tiene poca representación, como podemos observar en el siguiente apartado, en la Tabla 1 sobre el análisis de las bases de datos terminológicas existentes. La información traductológica relacionada con las estrategias y técnicas de traducción, las traducciones incorrectas o los comentarios para la traducción serían elementos de gran utilidad para un traductor.

Un trabajo terminológico orientado a la traducción debería contener información contrastiva sobre el campo temático y las propuestas de traducción. En este sentido, mencionamos el proyecto LAW10n sobre el derecho informático (contratos de licencia de programas informáticos) en la combinación lingüística inglés-español, que presenta una metodología basada en un modelo integrador para la toma de decisiones en traducción jurídica (Prieto Ramos, 2013). El proyecto LAW10n refleja un salto de las fichas terminológicas tradicionales a las fichas traductológicas, que contienen información útil para la actividad de traducción; por ejemplo, los comentarios de traducción y las propuestas separadas para encargos: traducción documento o instrumento (Prieto Ramos y Orozco Jutorán, 2015).

Otra propuesta de superar las limitaciones acerca de la información que contienen los diccionarios incluye fichas terminológicas para la traducción, con información contrastiva resultante del proceso de determinación del grado de aceptabilidad de la equivalencia: casi absoluta, parcial y nula (Šarčević, 1997), así como campos como texto paralelo y texto normativo (Cornea, 2015).

A partir de estos datos, determinamos emplear fichas traductológicas, en vez de terminológicas, ya que se diferencian en varios aspectos. Uno de ellos es que las primeras parten de un único concepto en la lengua original y recogen las variantes de traducción en la lengua meta en una única ficha, no en fichas separadas, aportando también rubros novedosos en este ámbito, como las opciones no recomendadas. Descartamos incluir información sobre las técnicas de traducción en una categoría de datos separada en la ficha ENALLTerm, como sí se presenta en el proyecto LAW10n, ya que México cuenta con muy pocos programas de formación de traductores y estimamos que imponer una nomenclatura de técnicas puede causar más confusión. No obstante, en las notas para la traducción se mencionan diferentes técnicas de traducción, como podemos observar en el 
siguiente ejemplo extraído de una ficha ENALLTerm del término happy spitter (glosario de farmacología):

Notas para la traducción: Consideramos que el equivalente más natural sería "vomitador sano"; sin embargo, el más frecuente que aparece en los textos en español es el de "vomitador feliz", que es la traducción literal del término en inglés (Armijo et al., 2019).

La necesidad del traductor profesional es poder formar sus propios argumentos para comprender las UT en ambas lenguas y contextos, y emplearlas de forma adecuada.

En consecuencia, para contribuir a mejorar el panorama de los recursos terminológicos para la traducción, diseñamos la base de datos traductológica ENALLTerm, la cual contiene fichas traductológicas, cuyo fin es brindar al traductor información traductológica reflejada en campos innovadores en este terreno, así como las opciones no recomendadas, los comentarios para la traducción y los contextos multimedia.

\section{Metodología de trabajo}

La metodología de la investigación se compone de varias fases, las cuales describimos a continuación.

Partimos de un análisis de las bases de datos existentes en la combinación inglés, francés o alemán al español, con la finalidad de observar la perspectiva de dichos productos en relación con la actividad de traducción. Para ello, analizamos las bases de datos terminológicas más grandes en cuanto al número de términos que contienen (IATE, 8 millones de términos; EuroTermBank, 14 millones de términos; Termium Plus, 4 millones de términos).

Los recursos lexicográficos y terminológicos cuentan con una estructura textual que se diferencia en varios niveles: superestructura/hiperestructura (la estructura global que ordena los componentes de un recurso), macroestructura (la organización de las unidades léxicas), microestructura (conjunto de categorías de datos), iconoestructura (explicación a través de las imágenes), estructura referencial (remisiones) (Gelpí Arroyo, 2000, pp. 10-15; Rafel i Fontanals, 2005, pp. 84-101).

Para este estudio, nos focalizamos en la microestructura, con el fin de observar cómo se presenta la información lingüística y conceptual. Cada indicación transmite un tipo de información concreto o la información se puede representar en varias indicaciones. Agrupamos las indicaciones según su función. Así que proponemos las siguientes categorías: "mecanismos para descodificación del significado", donde incluimos la definición (Lorente, 2001, pp. 104-112); "mecanismos de apoyo conceptual", cuya función es ayudar a una mejor comprensión del significado (contexto, imágenes, audios, videos) (Lázaro, 2015; Lázaro y Cornea, 2019) y, por último, agregamos la categoría de "mecanismos de apoyo conceptual para la traducción", como los comentarios de traducción, las propuestas separadas para encargos: traducción documento o instrumento, técnicas de traducción, textos paralelos, etc. (Cornea, 2015; Prieto Ramos y Orozco Jutorán, 2015).

Como se observa en la Tabla 1, de las 15 bases de datos terminológicas, solo 9 incluyen la definición en el término (la lengua de partida) y 7 abarcan también la definición del equivalente (lengua de llegada). Los contextos en formato texto se representan en 5 recursos, mientras que solo 1 retoma imágenes. En cuanto a los mecanismos de apoyo para la traducción, 9 recursos presentan comentarios o notas, 1 recurso tiene opciones no recomendadas (Termium Plus) y 7 retoman variantes. Cabe mencionar 


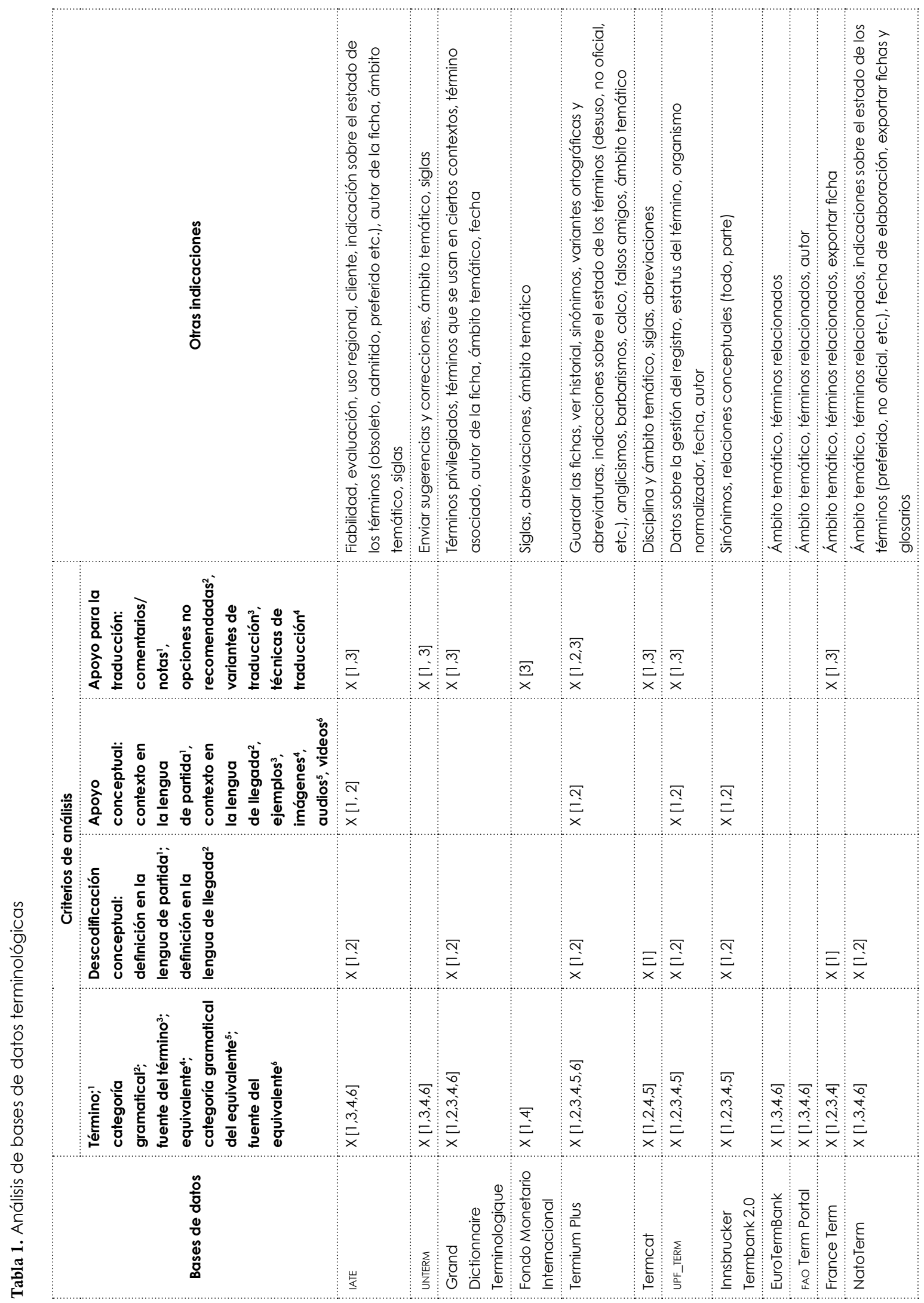

479

Mutatis Mutandis. Revista Latinoamericana de Traducción

Vol. 14, $N .{ }^{\circ}$ 2, 2021, julio-diciembre, pp. 469-493 


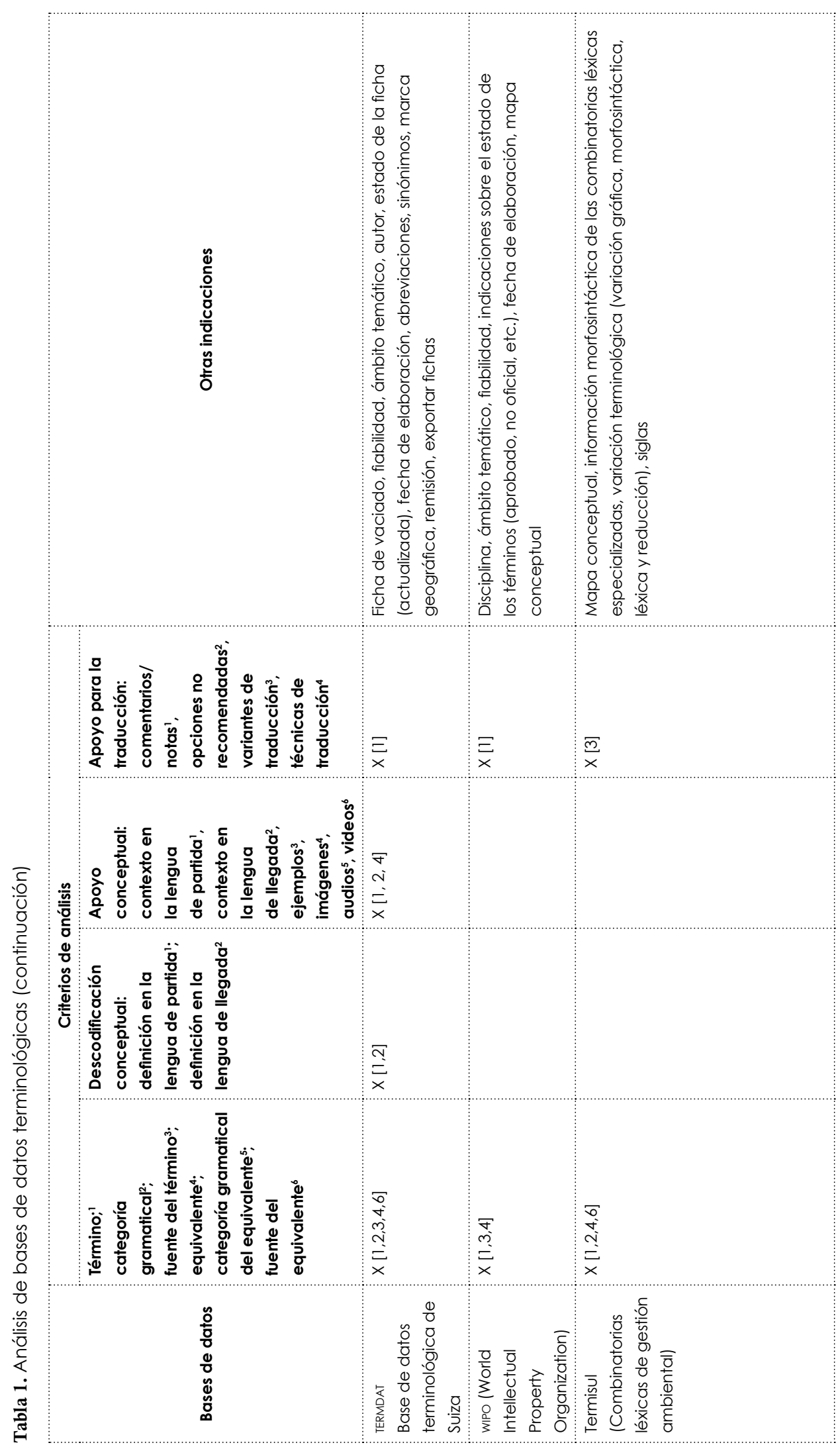

Nuevas perspectivas de investigación en la traducción especializada en lenguas románicas: aspectos comparativos, léxicos, fraseológicos, discursivos y didácticos 
que Termium Plus es un recurso muy útil en la combinación lingüística inglés-francés, pero el español apenas se está incorporando. En el rubro de análisis de "Otras indicaciones", notamos categorías de datos interesantes, como el ámbito temático, remisiones y sinónimos, la posibilidad de guardar y exportar las fichas, fecha y autor, entre otras.

A partir de estas premisas, delimitamos los campos de la ficha traductológica y realizamos una encuesta para obtener la opinión del público meta. La ficha se propone contestar tanto a la necesidad léxica reflejada en el equivalente en español como a la necesidad conceptual representada mediante la definición, contexto (texto y archivos multimedia) y a la necesidad traductológica dada, por medio de las variantes de traducción, opciones no recomendadas y comentarios para la traducción.
Con la finalidad de sistematizar las necesidades lingüísticas y conceptuales de los traductores e intérpretes, y observar la utilidad de la ficha traductológica que diseñamos para la base de datos ENALLTerm, elaboramos una encuesta que se compone de dos secciones: la primera se refiere a los datos de los encuestados acerca de su experiencia (años, estudios, combinación de lenguas, si es traductor/intérprete profesional/ocasional); la segunda se compone de dos tipos de fichas traductológicas, con varios rubros que podían ser de gran ayuda para el traductor e intérprete en su actividad profesional. La diferencia entre las dos fichas consiste en que una contenía contextos multimedia: audio, video e imagen, y la otra no.

Se les pidió a los encuestados analizar las dos fichas (véanse Figuras 1 y 2) y calificarlas con

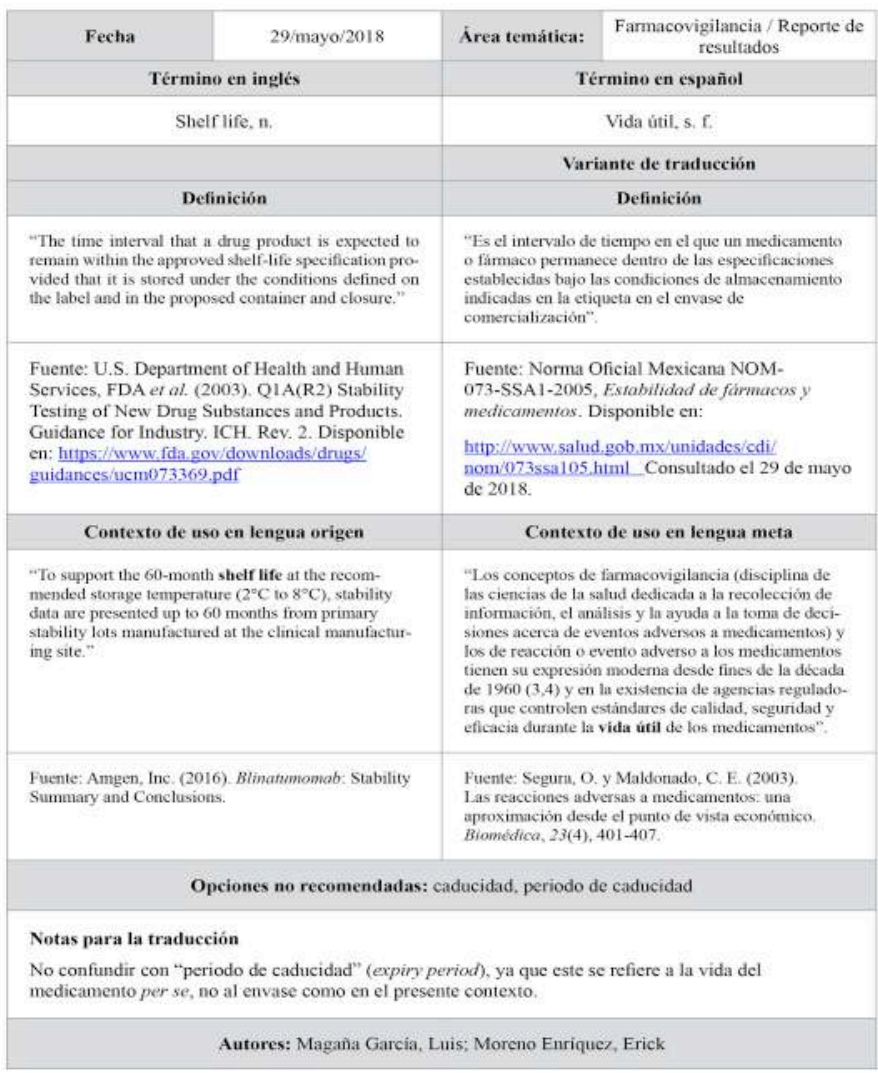

Figura 1. Ficha traductológica sin contextos multimedia 


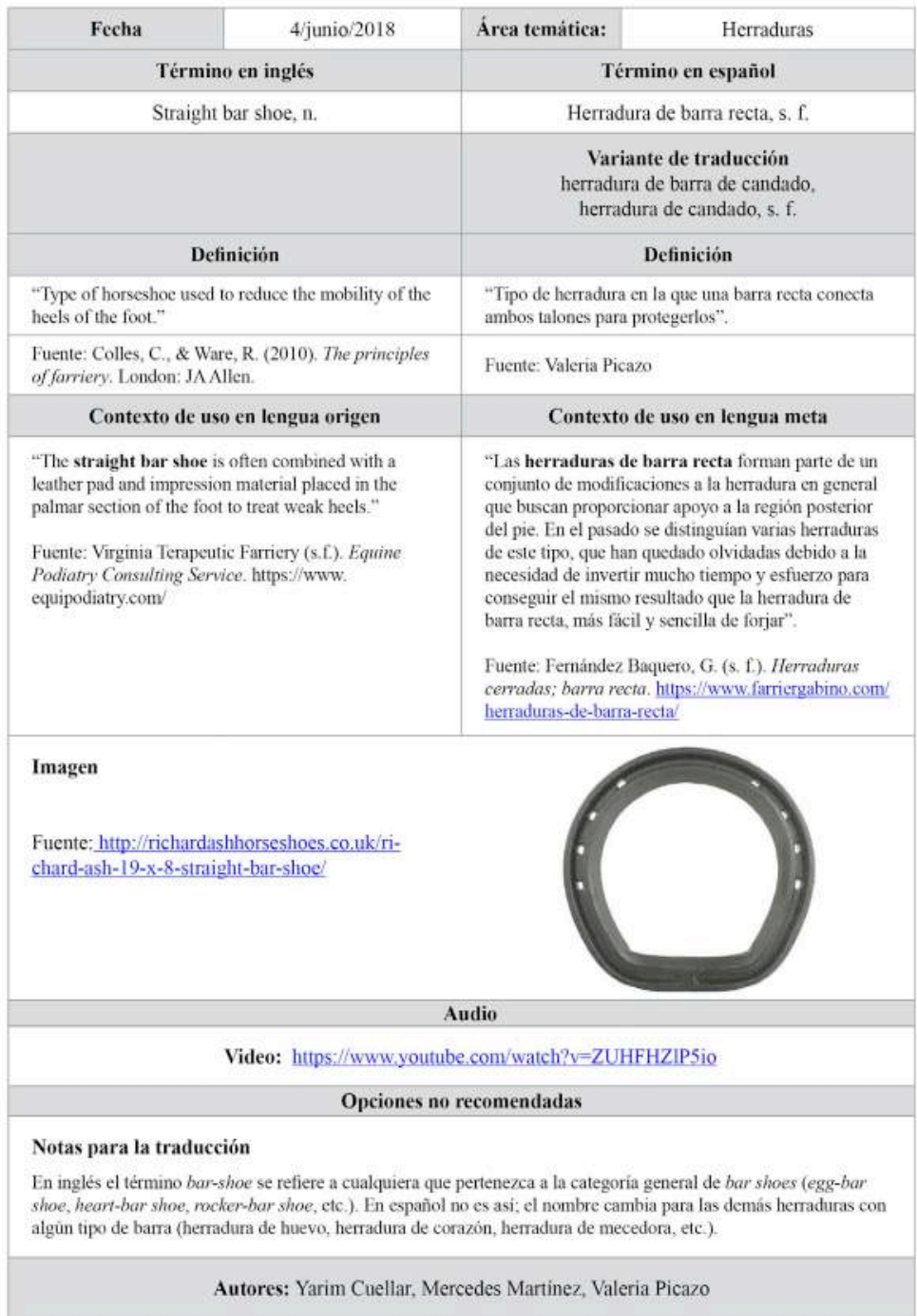

Figura 2. Ficha traductológica con contextos multimedia

una escala de 1 a 5 (1 siendo el menor puntaje y 5 el mayor), atendiendo a la utilidad de dichas fichas para la actividad de traducción/interpretación. Además, se les requirió mencionar si consideraban necesario otro elemento, rubro o categoría de datos a la ficha, y cuál era éste. Por último, se les pidió mencionar en qué campo/subcampo le serviría más la base de datos.

La encuesta se llevó a cabo con la ayuda de la herramienta Google Forms y se difundió a través del Departamento de Traducción e Interpretación de la ENALLT, dado que cuenta con una base de datos de traductores e intérpretes de todo el país. Recibimos 109 respuestas.

En cuanto al perfil de los encuestados, el 12,8\% eran estudiantes de traducción, el $16,5 \%$ profesores de traducción, el 48,6 \% traductores profesionales, un $16,5 \%$ traductores ocasionales, un $4,6 \%$ intérpretes profesionales, el 9,2\% intérpretes ocasionales, el 14,7\% traductores/ intérpretes profesionales y el $11,9 \%$ traductores/intérpretes ocasionales. 
E1 $76 \%$ de los encuestados calificó como muy útil la ficha que contiene datos multimedia; por esta razón, decidimos incluir este tipo de información. Esto implica un avance en la elaboración de fichas terminológicas para la traducción, ya que, según el análisis que realizamos, no encontramos ningún recurso terminológico que contenga contextos textuales y multimedia en una misma ficha.

Otra categoría de datos que resultó interesante de la encuesta se refiere a la información geográfica del equivalente, ya que es importante para el traductor saber si se trata de un equivalente que se emplea en México u otro país de habla española, así como la sugerencia de imágenes y videos. Estos dos rubros se incluyeron en la versión final de la ficha.

En la Figura 3 se presentan las recomendaciones de los encuestados.
Asimismo, pudimos obtener datos sobre qué campos de especialidad se deberían recopilar en esta base (véase Figura 4).

Estos datos nos ayudaron a definir la estructura de la ficha, que contiene campos novedosos: 1) opciones no recomendadas, que recopilan formulaciones no adecuadas o incorrectas, desde el punto de vista lingüístico o traductológico, para el contexto de traducción; y 2) comentarios para la traducción, que contienen información complementaria que le sea de utilidad a un traductor. Estas categorías de datos también aparecen en la propuesta de Law10 (Prieto Ramos y Orozco Jutorán, 2015), pero la ficha ENALLTerm adopta un tratamiento bilingüe, mientras que la ficha traductológica Law10 no recopila la definición del equivalente, como tampoco archivos multimedia.

Las necesidades del traductor, que son de naturaleza léxica (en lengua de origen y
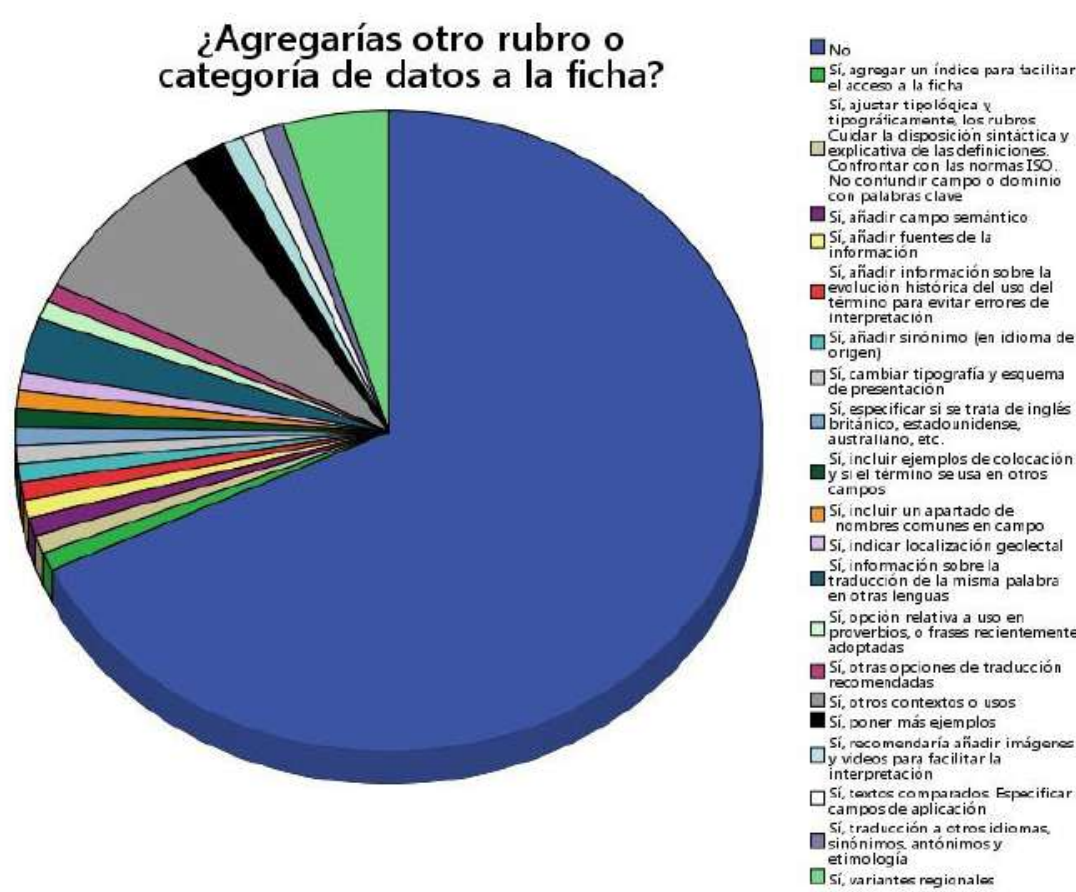

Figura 3. Recomendaciones de los encuestados 

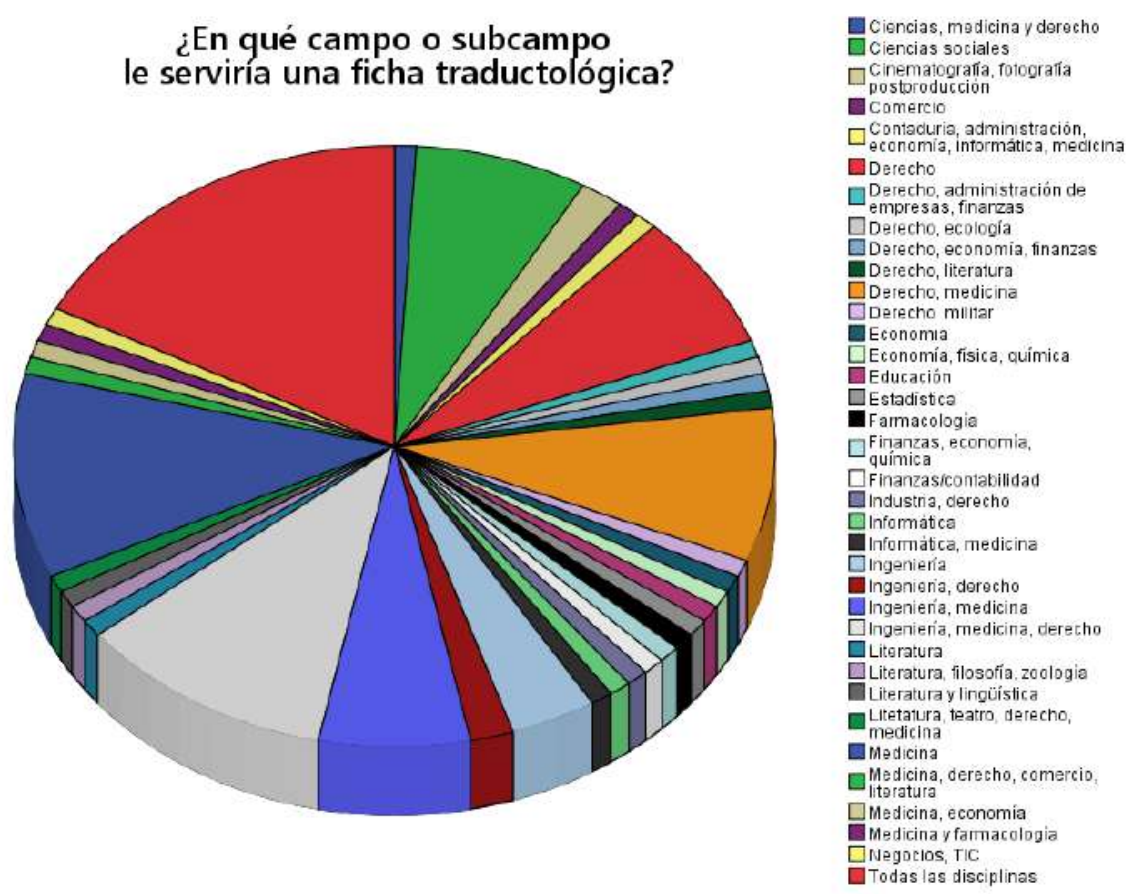

Figura 4. Recomendaciones de los encuestados sobre los campos de especialidad. Tic: Tecnologías de la información y la comunicación.

metaequivalentes), conceptual y textual, se ven reflejadas en el tipo de información que contiene la ficha, ya que la función de este producto es apoyar al traductor en el proceso de traducción y facilitarle la adquisición del conocimiento especializado de un ámbito de especialidad. Para tal fin, se propuso una estructura de la base de datos traductológica para formato digital (web), que permite la captura de las fichas, su revisión, publicación y consulta, en un portal desarrollado dentro de la Coordinación de la Educación a Distancia de la ENALLT-UNAM, un departamento multidisciplinario especializado en el desarrollo de materiales y aplicaciones educativas para la enseñanza y el aprendizaje de lenguas extranjeras, y traducción en ambientes digitales.

En la siguiente fase, determinamos la estructura de la base de datos traductológica y trabajamos en conjunto con el equipo técnico de
Coordinación de Educación a Distancia de la ENALLT para el desarrollo de la versión digital. Se montaron las librerías necesarias para la base de datos en el servidor asignado para su desarrollo y funcionamiento. Luego, realizamos el pilotaje de la base de datos en formato web e introdujimos los cambios necesarios.

La alimentación de la base de datos se hace de forma semiautomática mediante dos vías. Por un lado, a partir de los proyectos de terminología de los estudiantes de la Licenciatura en Traducción y del Diplomado en Traducción de Textos Especializados, revisados por los profesores del Departamento de Traducción e Interpretación de la ENALLT. Estos proyectos constan en la elaboración de un glosario en inglés, francés o alemán al español, lo que correspondería a un tipo de trabajo terminológico sistemático, ya que abarca un área de especialidad y sigue unas pautas metodológicas establecidas (Cabré y Tebé, 2005, p. 20). 
Para la construcción del corpus de vaciado (de extracción de los términos), se emplea Sketch Engine (s. f.), software de gestión de corpus y análisis de texto. La elaboración del corpus se puede hacer por medio de la selección y la recopilación manual de textos, o mediante la búsqueda y recopilación automática de textos directamente de Internet, a partir de palabras semillas (seed words). En este proceso, los alumnos combinan las dos modalidades, porque no siempre los resultados de la web son satisfactorios. Por tanto, crean un corpus comparable sobre un ámbito de especialidad en particular y emplean la aplicación Keywords para extraer terminología de forma automática tanto en una lengua como otra. Revisan y validan los términos obtenidos en la lengua de partida y después pasan a la alimentación de las fichas directamente en la base de datos ENALLTerm.

Algunos campos de la ficha, como lo detallamos más adelante, son obligatorios, como, por ejemplo, las lenguas, la definición, contextos con sus respectivas fuentes, el equivalente con su definición y su contexto y fuentes. Así que el estudiante empieza a rellenar el término en inglés, francés o alemán, y la información correspondiente, y luego completa el equivalente en español.

La búsqueda del equivalente se realiza en la lista de candidatos que se extrajo del corpus o directamente en el corpus en español, así como en otros recursos documentales (productos terminológicos y lexicográficos, otros corpus, revistas de especialidad) para validar la existencia del equivalente.

Ahora bien, uno de los problemas terminológicos es la falta de equivalencia y no siempre se puede conseguir una equivalencia terminológica, la que designa la misma realidad en la otra lengua. En estos casos, se aplica la técnica de traducción ${ }^{5}$ más adecuada para ese contexto y

5 No empleamos una clasificación específica de técnicas de traducción, ya que no existe una sola se menciona en las notas cómo se resolvió el problema.

Uno de los principios básicos del trabajo terminológico es que los términos no se traducen; sin embargo, este principio no se ha cumplido en muchas ocasiones, como bien mencionan Cabré y Tebé (2005, p. 21). Además, ENALLTerm es un recurso traductológico; por tanto, consideramos enriquecedor poder combinar las investigaciones de la traductología con la terminología.

Por otro lado, ENALLTerm se alimenta también de los talleres de traducción especializada, en los cuales los alumnos tradujeron textos especializados y realizaron glosarios sobre los temas de los textos a traducir, lo que corresponde a una terminología puntual, que se centra en un término o conjunto de términos de una misma área (Cabré y Tebé, 2005, p. 20). Esta práctica beneficia el almacenamiento y la recuperación de las uT tratadas en diferentes textos, ya que el alumno tiende a resolver los problemas terminológicos puntuales relacionados con cada traducción. No obstante, contar con una herramienta de este tipo facilita la creación de glosarios dentro de los talleres de traducción y permite la consulta de estos materiales por cualquier usuario interesado en distintos ámbitos de especialidad, incluso por el mismo alumno, quien tiende a realizar el mismo procedimiento documental para resolver los problemas asociados a la traducción de términos iguales o similares, por falta de gestión de la terminología.

clasificación para responder a los distintos tipos de traducción especializada que se enseña en la Licenciatura en Traducción de la ENALLT (jurídica, científico-técnicas, audiovisual, relaciones internacionales). Sin embargo, buscamos que las indicaciones sean más claras posibles y no utilizar nomenclaturas que puede dificultar la comprensión. 
Por último, las fichas validadas se publican en la base ENALLTerm.

\section{Plataforma web ENALLTerm}

La base de datos ENALLTerm, en su versión preliminar, se encuentra disponible en formato web y se puede consultar en el siguiente enlace: https://ced.enallt.unam.mx/enallterm/es. Todavía se está trabajando en la base; por eso, aquí presentamos los avances que tenemos hasta este momento, aunque esta información puede variar un poco hasta su versión final. A continuación se describen a detalle su estructura y contenido.

\subsection{Estructura de la página web}

La estructura de la página web está dividida en cinco secciones: "Inicio", "Búsqueda de fichas", "Contacto", "Quiénes somos" e "Iniciar sesión" (en la parte de arriba), lo que permite una navegación intuitiva con información fácil de entender (véase Figura 5).

En la pestaña "Inicio" se presentan tres secciones: "Información para el usuario", “¿Cómo realizar una búsqueda?" y "ENALLTerm FAQ", una sección sobre qué contiene y no contiene la base de datos, con qué ámbitos de especialidad trabaja, la estructura de las fichas y la fiabilidad de la información presentada.

La sección de "Búsqueda de fichas" indica los tipos de búsqueda que se pueden realizar: a través de palabras clave exactas y sin importar las mayúsculas; empleo de operadores booleanos (AND, OR, NOT); comillas para buscar una frase exacta, etc. Actualmente, la base cuenta con 700 fichas, que deben pasar por la fase revisión para que estén listas para su publicación.

A través de la sección de "Contacto", los usuarios podrán informar al equipo ENALLTerm sobre algún problema o colaborar con el proyecto, enviando información específica para alguna ficha o incluso un glosario completo.

En "Quiénes somos", se presenta el equipo de trabajo de este proyecto.

El apartado "Iniciar sesión" está reservado para aquellas personas que colaborarán con el proyecto: el estudiante que alimentará la base con sus fichas, el revisor experto en el área de especialidad y el revisor lingüista, que se encargará

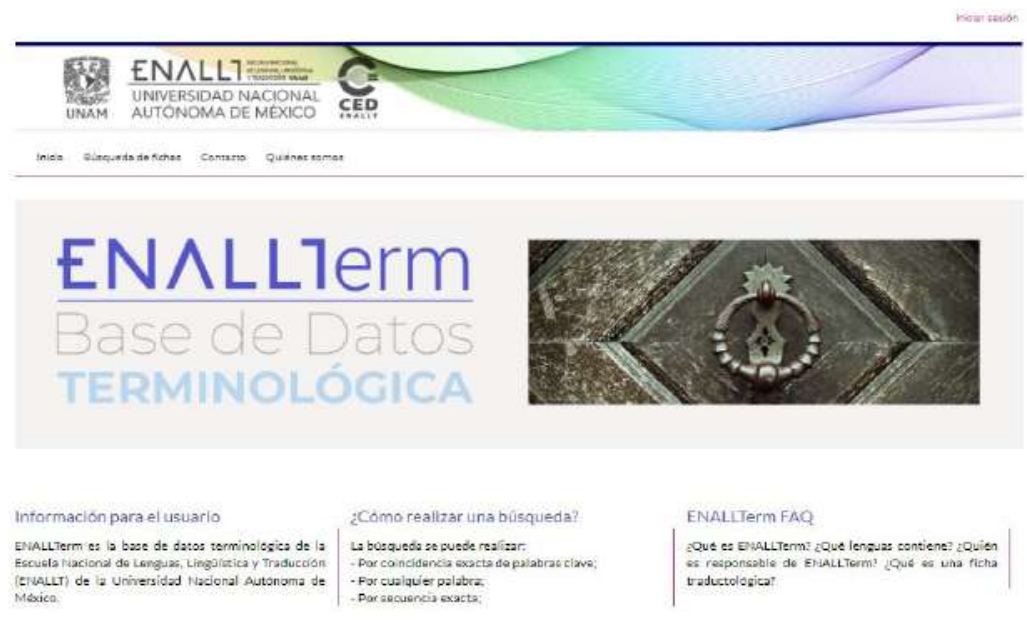

Figura 5. Página web enallterm 
de la corrección lingüística. Para ello, el administrador creará un usuario y una contraseña.

Para consultar la base no es necesario iniciar sesión, porque será de acceso libre y gratuito.

\subsection{La ficha traductológica}

La ficha ENALLTerm se compone de los siguientes campos (véase Figura 6)

1. Variante dialectal de la lengua seleccionada. Se elige la lengua de partida del término y la variante: inglés-EUA; inglés-RU; francés-FR, etc.
2. Área de especialidad. Se proporcionan cuatro áreas de especialidad, según la clasificación de la UNAM y de CONACyt (Consejo Nacional de Ciencia y Tecnología, institución dedicada a promover el avance de la investigación científica en México).

3. Disciplina. Se elige la disciplina correspondiente al término, relacionada a las cuatro áreas.

4. Temática en la cual se enmarca el término. Se escribe la temática correspondiente al término. Por ejemplo, si se eligió el área de "Ciencias sociales" y la disciplina de

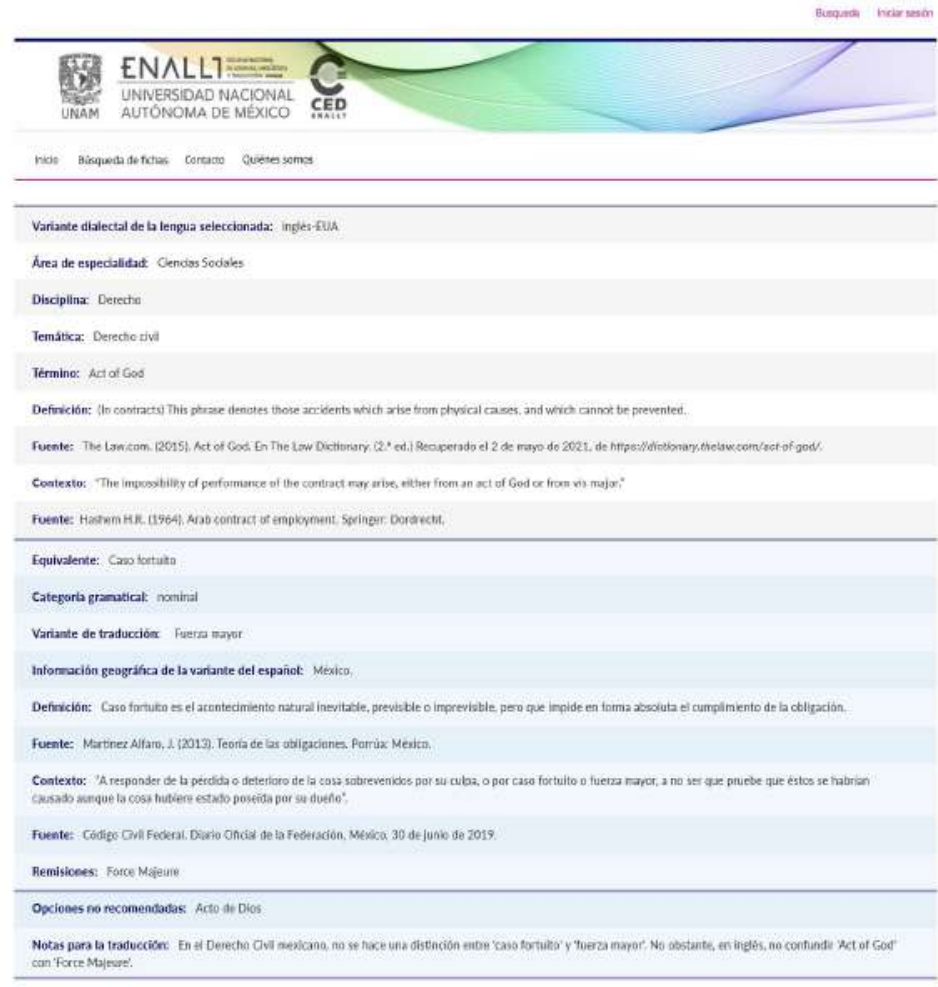

Figura 6. Ficha traductológica ENALLTerm 
"Derecho", la temática podría ser "Derecho civil", "Derecho penal", etc.

5. Término en la lengua de partida (inglés, francés o alemán). $\mathrm{El}$ término se extrae directamente de su contexto de uso, es decir, in vivo, con la finalidad de recopilar la terminología de la cual hacen uso los expertos. La recopilación se hace de forma semiautomática y los criterios de selección de los términos son la alta frecuencia en el corpus y la dificultad que implican esos términos para la traducción, como falta de equivalencia, variación denominativa, etc. Se prefieren las unidades pluriléxicas (p. ej. "Act of God”).

6. Definición del término y fuente. La definición del término en la lengua de partida. P. ej. "[Act of God:] (In contracts) This phrase denotes those accidents which arise from physical causes, and which cannot be prevented". Se menciona la fuente de donde se tomó la definición del término y se cita en formato normas APA: The Law Dictionary: https://dictionary. thelaw.com/act-of-god/. Si el alumno realiza la definición, entonces en este apartado indica su nombre.

7. Contexto del término y fuente. Se extrae el contexto en el que aparece el término "The impossibility of performance of the contract may arise, either from an act of God or from vis major." Hashem H. R. (1964). Arab contract of employment. Springer: Dordrecht.

Estos campos son obligatorios. Si no se rellena la información requerida, no se puede pasar a la siguiente fase, que corresponde al equivalente en español.

En la parte del español se requiere:

1. Equivalente en español. Se escribe el término equivalente en español. En el ejemplo de "Act of God", el equivalente es "Caso fortuito".

2. Categoría gramatical. Se elige la categoría gramatical del término en español.

3. Variante de traducción. Se indican otros posibles equivalentes en español. P. ej. una variante del término "Caso fortuito" es "Fuerza mayor".

4. Información geográfica de la variante del español. Se selecciona el país en donde se usa el término en español. P. ej. el término "Caso fortuito" se utiliza en México.

5. Definición del término en español y fuente. Se recopila la definición del término en español. P. ej. "Caso fortuito es el acontecimiento natural inevitable, previsible o imprevisible, pero que impide en forma absoluta el cumplimiento de la obligación". Fuente: Martínez Alfaro, J. (2013). Teoría de las obligaciones. Porrúa: México. Si el alumno realiza la definición, entonces en este apartado indica su nombre.

6. Contexto y fuente. Se especifica el contexto en donde aparece el término en español. P. ej. "A responder de la pérdida o deterioro de la cosa sobrevenidos por su culpa, o por caso fortuito o fuerza mayor, a no ser que pruebe que éstos se habrían causado, aunque la cosa hubiere estado poseída por su dueño". Fuente: Código Civil Federal. Diario Oficial de la Federación, México, 30 de junio de 2019.

Como en el caso de la lengua de partida, estos campos son obligatorios también en español. Una vez rellenada la información, se puede pasar al siguiente nivel, que no es obligatorio, ya que cada unidad terminológica presenta sus propias características. 
1. Contexto multimedia. Se agrega en el caso que fuera necesario los siguientes elementos: audio, video e imagen.

2. Remisiones. En caso de que el término en lengua de partida (p. ej. "Act of God") se relacione directamente con otro(s), p. ej. "Force Majeure", se escriben aquí los términos relacionados.

3 . Opciones no recomendadas. Se mencionan la o las traducciones incorrectas del término al español, como en este caso "Acto de Dios".

4. Notas para la traducción. Se agrega información complementaria que le sea de utilidad a un traductor. P. ej. "En el Derecho Civil mexicano, no se hace una distinción entre 'caso fortuito' y 'fuerza mayor'. No obstante, en inglés, no confundir 'Act of God' con 'Force Majeure"".

\subsection{Funciones de los usuarios}

En el proceso de elaboración de la plataforma web hemos decidido abarcar todas las posibilidades hasta tomar la decisión definitiva sobre la estructura de la plataforma, así como los diferentes usuarios. Hemos analizado y determinado el levantamiento de requerimientos, es decir, las cuestiones relacionadas con los usuarios (los diferentes roles), el objetivo del trabajo, el público meta (a quién va dirigido) y la función del producto. Para ello, hemos definido los roles de los participantes: 1) administrador (dar de alta a los alumnos, revisores, evaluadores); 2) alumno (quien crea la ficha); 3) revisor experto (revisor externo y experto en el contenido de las fichas, es decir, los ámbitos de especialidad); 4) evaluador (revisor interno experto en la lengua, es decir, quien se encarga de la revisión lingüística); y 5) usuario (público meta).

Determinar las funciones de cada participante no ha sido tarea fácil, ya que teníamos que delimitar muy bien en el rol de cada uno para que no se solaparan las actividades, así como prever diferentes escenarios. Se crearon diagramas de procesos y mapas de navegación para cada rol, lo que corresponde a las funciones que tiene cada participante, que presentamos en la Figura 7.

El perfil del administrador cuenta con la función de dar de alta a los alumnos, revisores expertos, evaluadores, según corresponda con la finalidad que utilicen el sitio web, y contar con una visión general del estado de las fichas:

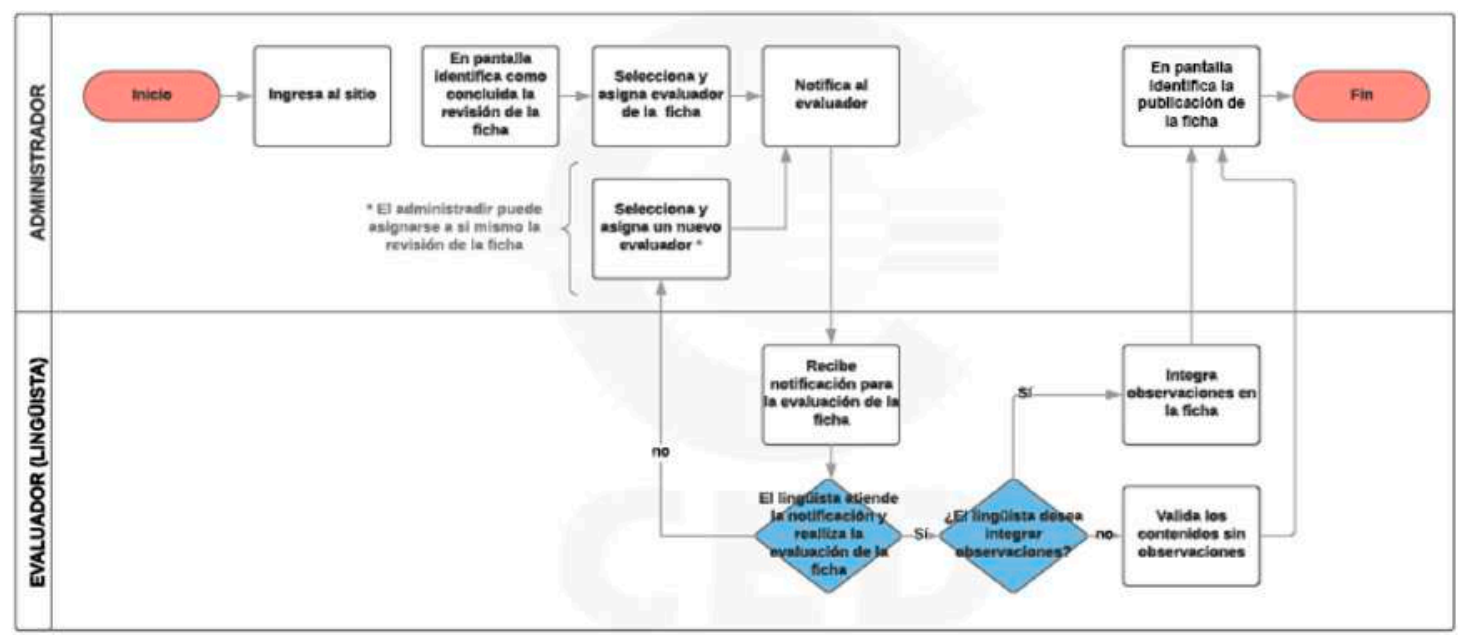

Figura 7. Diagrama de proceso administrador/evaluador 
cuántas se encuentran en captura, cuántas se enviaron a los revisores, cuántas se publicaron.

El perfil de alumno permite la posibilidad de crear una ficha y rellenar los campos, así como borrar o modificar la información de la ficha antes de enviarla a revisión.

En cuanto al revisor experto, este perfil tiene habilitados ciertos campos de la ficha que tienen que ver más bien con la información conceptual de un ámbito de especialidad en concreto. Estos campos son: el término en español, el equivalente en español y las variantes de traducción, definición y su fuente, contexto y su fuente. El revisor experto sugiere los cambios en una ventana habilitada para esto y puede hacer un comentario global de la ficha.

El perfil del evaluador lingüista tiene la función de editar todos los campos de la ficha, una vez que el revisor experto haya presentado su dictamen. Este perfil también permite la publicación de las fichas en la plataforma ENALLTerm para su consulta externa.

El usuario externo o el público meta no podrá alimentar directamente la base de datos; solo podrá realizar búsquedas dentro de ella y acceder a las fichas existentes, así como contactar al equipo en el caso de que quiera colaborar o indicar algún error o cambio en alguna de las fichas publicadas. Si alguien fuera de la ENALLT quisiera colaborar con el proyecto, se le creará una cuenta (usuario y contraseña) y podrá acceder a través de la sección "Iniciar sesión", ubicada en la parte izquierda de la cabecera.

\section{Conclusiones}

La creación de la base de datos traductológica ENALLTerm se suma a los esfuerzos por superar las limitaciones de los productos terminológicos para la traducción y presentar un recurso diseñado en función de las necesidades de los traductores. Este instrumento pretende mejorar la calidad de las traducciones en diversos campos, haciendo la búsqueda de los términos y el proceso de adquisición del conocimiento conceptual de un ámbito en particular más eficiente y práctico, a través de los diferentes campos presentados en la ficha: definición, contexto, información complementaria en formato multimedia, comentarios para la traducción.

ENALLTerm se propuso romper con la estructura clásica de este tipo de productos, a la par de aprovechar el espacio digital para crear fichas con información lingüística, conceptual y traductológica.

Cabe resaltar que, a partir de la teoría sobre la competencia traductora y las necesidades de los traductores en el proceso de traducción, pudimos delimitar los campos de la ficha, que deja de ser simplemente terminológica y pasa a ser traductológica, por contener información útil para los traductores, como los campos de opciones no recomendadas o notas para la traducción.

La realización de la encuesta ha aportado, además, datos interesantes para el proyecto, ya que los encuestados son los mismos usuarios, así que preguntarles sobre la utilidad de los campos existentes y brindarles la oportunidad de proponer otros nos ayudó a identificar algunas necesidades lexicográficas de los traductores especializados, las cuales podían ser atendidas por los campos de la ficha.

Asimismo, integrar a los alumnos de traducción de la ENALLT en el proceso de recopilación de corpus y creación de fichas les permite aprender sobre la metodología de creación de glosarios y participar de forma activa en la comunicación de conocimiento especializado, a través de la elaboración de fichas traductológicas recopiladas en un producto constituido en función de las necesidades del traductor en cada una de las fases del proceso traductor. 
En conclusión, ENALLTerm pretende ser una herramienta de apoyo para los traductores especializados, para ayudarles a optimizar los tiempos de búsqueda y estar mejor informados para la toma de decisiones, ya que muchos diccionarios existentes no ofrecen los datos necesarios para poder crear criterios propios en cuanto a un término $u$ otro, sino que a veces confunden más a los usuarios, por no contener información semántica o pragmática. Contar con doble revisión de las fichas favorece obtener mayor calidad de la información presentada $\mathrm{y}$, por ende, tiene también un impacto en la calidad de las traducciones y la gestión del proceso traductor.

Los avances tecnológicos contribuyeron al diseño de esta base de datos en formato web $\mathrm{y}$, en un futuro, ENALLTerm estará disponible para las aplicaciones móviles Android y iOs. Esto favorecerá el acceso desde distintos dispositivos, y pondrá al servicio de los alumnos de traducción, traductores profesionales $\mathrm{o}$ cualquier interesado, una terminología necesaria, porque, al fin y al cabo, la terminología es parte de nuestra vida cotidiana.

\section{Referencias}

Armijo, M., Melo, C., Pérez, C. y Robledo, M. (2019). Happy spitter. En ENALLTerm. https:// ced.enallt.unam.mx/enallterm/es

Bestué Salinas, C. (2016). Translating law in the digital age. Translation problems or matters of legal interpretation? Perspectives, 24(4), 576-590. https://doi.org/10.1080/090767 6X.2015.1070884

Biel, L. (2008). Legal terminology in translation practice: dictionaries, googling or discussion forums? SKASE Journal of Translation and Interpretation, 3(1), 22-38. http://www.skase. sk/Volumes/JTI03/pdf_doc/BielLucja.pdf

Cabré, M. T. (1999). La terminología: representación y comunicación. Elementos para una teoría de base comunicativa y otros artículos. Universitat Pom- peu Fabra, Institut Universitari de Lingüística Aplicada.

Cabré, M. T., Domènech Bagaria, O. y Estopà Bagot, R., (2018). La terminologia avui: termes, textos $i$ aplicacions. Editorial UOC.

Cabré, M. T. y Estopà, R. (2002). El conocimiento especializado y sus unidades de representación: diversidad cognitiva. Sendebar, (13), 141-153. https://xdocs.cz/doc/2-1-1-lectura-el-conocimiento-especializado-y-sus-unidadespdf-d8m $1 \mathrm{mgm} \times 528 \mathrm{p}$

Cabré, M.T. y Estopà, R. (2005). Unidades de conocimiento especializado: caracterización y tipología. En M. T. Cabré y C. Bach (Eds.), Coneixement, llenguatge $i$ discurs especialitzat (pp. 69-93). Institut Universitari de Lingüística Aplicada. Universitat Pompeu Fabra; Documenta Universitaria.

Cabré, M. T. y Tebé, C. (2005). El trabajo terminológico multilingüe de enriquecimiento lingüístico: una propuesta metodológica. Revista Española de Lingüistica Aplicada, (1), 19-41. https://dialnet.unirioja.es/servlet/articulo?codigo $=1998012$

Cornea, I. (2015). Unidades de conocimiento especializado para la traducción jurídica: identificación y propuesta de representación de del derecho de extranjería en un diccionario bilingüe español-rumano [Tesis doctoral] Departamento de Traducción y Ciencias del Lenguaje, Universitat Pompeu Fabra, Barcelona. http://hdl.handle. net/10803/295967

Durão, A., Sastre Ruano, $\mathrm{M}^{\mathrm{a}}$ A. y Werner, R. (2012). Lexicografía didáctica, diccionario bilingue y lenguas afines: información semántica en el Diccionario Contrastivo Portugués-Español (DiCoPoEs). En A. Nomdedeu, E. Forgas y M. Bargalló (Eds.), Avances en lexicografia hispánica (Tomo II, pp. 69-78). Servei de Publicacions de la Universitat Rovira i Virgili.

Fuertes Olivera, P. A. y Tarp, S. (2008). La teoría funcional de la lexicografía y sus consecuencias para los diccionarios de economía del español. Revista de Lexicografia, 14, 75-95. https:// doi.org/10.17979/rlex.2008.14.0.3840 
Gelpí Arroyo, C. (2000). La lexicografia. Grupo Santillana de Ediciones.

Hurtado Albir, A. (2007). Competence-based curriculum design for training translators. The Interpreter and Translator Trainer, 1(2), 163-195. ttps:// doi.org/10.1080/1750399X.2007.10798757

Hurtado Albir, A. (2017). Translation and translation competence. En A. Hurtado Albir (Ed.), Researching Translation Competence by PACTE Group (pp. 3-35). John Benjamins.

Kelly, D. (2008). Training the trainers: Towards a description of translator trainer competence and training needs analysis. TTR. Traduction, terminologie, rédaction, 21(1), 99-125. https:// doi.org/10.7202/029688ar

Kelly, D. (2014). A handbook for translator trainers. Routledge.

Lázaro, J. (2015). El ejemplo en terminología. Caracterización y extracción automática [Tesis doctoral]. Institut Universitari de Lingüística Aplicada, Universitat Pompeu Fabra, Barcelona.

Lázaro, J. y Cornea, I. (2019). El principio de adecuación en diccionarios especializados multilingües. Un caso de estudio en el área de turismo. En G. Lima Moreira, y G. Eres Fernández (Eds.), Enseñanza de español con fines específicos: el caso de la carrera de Turismo. Teoría y práctica (pp. 164-178). Editorial Consejería de Educación de España en Brasil.

Lorente, M. (2001). Teoría e innovación en terminografía: la definición terminográfica. En M. Cabré, J. Feliu (Eds.), La terminología cientifico-técnica: reconocimiento, análisis y extracción de información formal y semàntica (pp. 81-112). Institut Universitari de Lingüística Aplicada. Universitat Pompeu Fabra.

Montané March, M. A. (2016). E1 trabajo terminológico sistemático: su aplicación para la elaboración de bancos de datos terminológicos. En S. Alvarez Catalá y M. Barité (Coords), Teoría y praxis en terminología (pp. 113133). Ediciones Universitarias.

Naciones Unidas. (2013). UNTERM. The United Nations Terminology Database. https://unterm. un.org/unterm/portal/welcome
Nielsen, S. (2010). Specialized translation dictionaries for learners. En P. A. FuertesOlivera (Ed.), Specialized dictionaries for learners (pp. 69-82). De Gruyter.

Nord, C. (1991). Text analysis in translation. Rodopi.

Orozco-Jutorán, M. (2017). Efficient search for equivalents at your fingertips - The specialized translator's dream. Meta, 62(1), 137-154. https://doi.org/10.7202/1040470ar

PACTE. (2003). Building a translation competence model. En F. Alves (Ed.), Triangulating translation. Perspectives in process oriented research (pp. 43-66). John Benjamins.

PACTE. (2014). First results of PACTE group's experimental research on translation competence acquisition: The acquisition of declarative knowledge of translation. MonTI, (1), 85-115. https://www.e-revistes.uji.es/index.php/ monti/article/view/1702

PACTE. (2018). Competence levels in translation: Working towards a European framework. The Interpreter and Translator Trainer, 12(2), 111-131. https://doi.org/10.1080/175039 9X.2018.1466093

Prieto Ramos, F. (2013). ¿Qué estrategias para qué traducción jurídica?: por una metodología integral para la práctica profesional. En I. Alonso Araguás, J. Baigorri Jalón y H. Campbell (Eds.), Translating the law. Theoretical and methodological issues / traducir el derecho. Cuestiones teóricas y metodológicas (pp. 87-106). Comares.

Prieto Ramos, F. y Orozco Jutorán, M. (2015). De la ficha terminológica a la ficha traductológica: hacia una lexicografía al servicio de la traducción jurídica. Babel, 61(1), 110-130. https:// doi.org/10.1075/babel.61.1.07ram

Rafel i Fontanals, J. (2005). Lexicografia (Vol. 94). Editorial Uoc.

Šarčević, S. (1997). New approach to legal translation. Kluwer Law International.

Sketch Engine (s. f.) [Página web]. https://www. sketchengine.eu/

Tarp, S. (2008). Lexicography in the borderland between knowledge and non-knowlegde. Max Niemeyer Verlag. 
Tarp, S. (2010). Functions of specialised lerner's dictionaries. En P. Fuertes-Olivera (Ed.), Specialised Dictionaries for Learners (pp. 39-52). De Gruyter.

Tarp, S. (2014). Reflexiones sobre el papel y diseño de los diccionarios de traducción especializada. MonTI, (6), 63-89. https://doi.org/10.6035/ MonTI.2014.6.2
Unión Europea. (2021). IATE: Interactive Terminology for Europe. https://iate.europa.eu/home

Van Laer, C. J. P. (2014). Bilingual legal dictionaries: Comparison without precision? En M. Mac Aodha (Ed.), Legal lexicography. Ashgate.

Cómo citar este artículo: Cornea, I. (2021). ENALLTerm: hacia una base de datos al servicio de la traducción especializada. Mutatis Mutandis, Revista Latinoamericana de Traducción, 14(2), 469-493. https://doi.org/10.17533/udea.mut.v14n2a09 